\title{
Capacitando profissionais em saúde, trabalho e meio ambiente
}

\author{
Capacitation of professionals in health, work \\ and environment: an interdisciplinarity teaching \\ approach for sustainable development
}

Raquel Maria Rigotto 1 Vera Lúcia de Almeida 2
1 Professora do Departamento de Saúde Comunitária da Universidade Federal do Ceará. Coordenadora do Curso de especialização em Saúde, Trabalho e Meio Ambiente para o Desenvolvimento Sustentável.

2 Professora do Departamento de Enfermagem da Universidade Federal do Ceará. Membro do Colegiado de Coordenação do Curso.
Abstract Northeastern Brazil, in particular the State of Ceará, is currently undergoing profound territorial, demographic, economic and social changes brought about the transnational movement of Globalization and Productive Restructuring. This movement may, depending on how it is dealt with, produce a serious impact on the general life quality and thus compromise the perspective of a sustainable society in the future. The Federal University of Ceará, wishing to fulfill its social function in this process, has implanted a Specialization Course in Health, Work and Environment for Sustainable Development to prepare professionals in these areas. The Course inovates by presenting a broad and complex thematic scope (the interrelations between health, work and environment), an eminently multiprofessional group of participants, and an attempt at building up a teaching-and-learning methodology with a neatly interdisciplinarity approach. This article also presents the course program, divided in four parts and disciplines. The strategies used in the practice of interdisiciplinarity are described, the difficulties are assessed and the organization of the academic production is shown.

Key words Capacitation; Methodology; Interdisciplinarity
Resumo O Nordeste do Brasil - em particular, o estado do Ceará - está colocado diante de um quadro de profundas modificações territoriais, demográficas, econômicas e sociais conduzidas pelo movimento transnacional de globalização e de reestruturação produtiva, que pode, dependendo da forma como for conduzido, trazer sérios impactos sobre a qualidade de vida da população, comprometendo a perspectiva de avanço para uma sociedade sustentável. Em tal contexto, a Universidade Federal do Ceará implantou o Curso de Especialização em Saúde, Trabalho e Meio Ambiente para o Desenvolvimento Sustentável na tentativa de cumprir sua função social, capacitando atores sociais para intervirem neste processo. O Curso oferece, como características inovadoras, a definição de um campo temático abrangente e complexo - relações entre saúde, trabalho e meio ambiente-, um corpo discente eminentemente multiprofissional e a busca permanente da construção de metodologia de ensino-aprendizagem que contemple a abordagem interdisciplinar do objeto. O artigo apresenta o Programa do Curso, dividido em quatro módulos e suas disciplinas; descreve as estratégias que têm sido adotadas na prática da interdisciplinaridade; avalia as dificuldades encontradas; e exemplifica como está sendo organizada a produção acadêmica.

Palavras-chave Capacitação; Metodologia; Interdisciplinaridade 


\section{Introdução}

O estado do Ceará insere-se na região Nordeste do Brasil, uma das mais pobres do país. Conta com 6.812.575 habitantes (1996), dos quais $31,6 \%$ são analfabetos e $43,8 \%$ têm renda mensal de até 200 dólares (IPLANCE, 1997). Classificado de acordo com o Índice de Desenvolvimento Humano - IDH, do Programa das Nações Unidas para o Desenvolvimento - PNUD, situa-se no 23o lugar entre os 26 estados brasileiros e, no ranking dos países selecionados, divide com Papua-Nova Guiné a 126a posição (PNUD, 1996).

Atualmente, esta região - de tradição marcadamente agro-pastoril e com elevada dívida social acumulada - tem passado por profundas modificações relacionadas à forma como vem se inserindo no processo de globalização e de reestruturação produtiva, alterações estas que, ante o caráter seletivo do processo, nem sempre significam desenvolvimento para o conjunto da população. De um lado estão as áreas tradicionais - como as zonas canavieiras e o semi-árido -, onde a questão fundiária continua intocada e que, longe da perspectiva de inserir-se no movimento da competitividade, estão por ele fragilizadas e ameaçadas. De outro lado encontram-se os chamados 'pólos dinâmicos' - como o têxtil e de confecções, entre outros, da capital do estado que podem ser espaços 'que interessam' aos novos atores globais, reproduzindo desigualdades espaciais e sociais já seculares na região (Bacelar, 1997).

No caso do Ceará, os últimos planos de governo em nível estadual que compõem o denominado Plano de Desenvolvimento Sustentável - centram suas iniciativas na promoção da industrialização e do turismo, para o quê devem receber verbas do governo federal, além de outros recursos de agências multilaterais, criando infra-estrutura para atrair o capital privado. Grandes investimentos estão sendo feitos em rodovias e ferrovias, porto e aeroporto, linhas de eletrificação e de telefonia, gasodutos etc. Uma das grandes obras - já iniciada - é a construção do Complexo Industrial e Portuário do Pecém, voltado à petroquímica, siderurgia e metal-mecânica, para onde o governo pretende atrair cerca de duzentas empresas, gerando 30 mil empregos diretos e 150 mil indiretos, em uma região até agora caracterizada pela pesca e agricultura de subsistência. Cidades próximas à capital, como Hori- zonte e Pacajús, e mesmo outras, no interior, têm recebido indústrias atraídas por incentivos e isenções oferecidos pelo governo, totalizando, nos últimos cinco anos, 355 empresas. Anunciam-se, assim, profundas alterações da paisagem e da organização social.

Este processo, embora indique a perspectiva do crescimento do estado - da ampliação de seu PIB - e se revista de relevância social pela geração de emprego e renda, não tem sustentabilidade garantida de antemão. $\mathrm{O}$ que a experiência histórica vem demonstrando é o predomínio quase hegemônico do econômico sobre o social; a visão da economia como fim em si mesma, em que o ser humano é considerado apenas como recurso e/ou como consumidor, deixa de lado valores como a eqüidade, a solidariedade e a justiça social (OPAS, OEA, PNUD, PNUMA, BID e BANCO MUNDIAL, 1995:3).

No contexto atual de globalização da economia e da nova divisão internacional do trabalho é possível que o perfil das indústrias que procuram implantar-se em regiões como o Nordeste brasileiro tenda a ser o daquelas que têm processo produtivo mais poluente, consumidor de recursos naturais e com condições de trabalho mais precárias (Bacelar, 1997). Tais empresas, atraídas pelas facilidades de infraestrutura e por isenções de impostos oferecidas pelos governos, muitas vezes estão também fugindo do rigor da legislação e da fiscalização em regiões/países com mais experiência acumulada nas questões de saúde e meio ambiente - hoje, definitivamente inseridas na agenda social das regiões desenvolvidas - como fruto de penoso aprendizado. Somem-se a semelhantes 'facilidades', os baixos graus de instrução, cidadania e organização da população - fatores que, juntos, podem facilitar a implantação de um processo de desenvolvimento pouco sustentável na perspectiva da qualidade de vida do conjunto da população e das gerações futuras.

Do ponto de vista sociopolítico, o desafio que se apresenta é a integração das dimensões econômica e social do desenvolvimento. As tensões criadas pelo reordenamento nas relações de trabalho no confronto entre o global e o local exigem, por um lado, profundo conhecimento teórico-empírico acerca das dimensões do trabalho, da saúde e do meio ambiente, fundamental para a definição do projeto de desenvolvimento sustentável. Assim, ainda há muito a ser feito para garantir o pri- 
meiro princípio da Declaração do Rio sobre Meio Ambiente e Desenvolvimento:

"Que os seres humanos são o centro de preocupação para o desenvolvimento sustentável e que têm direito a uma vida saudável e produtiva, em harmonia com a natureza." (Conferência das Nações Unidas sobre Meio Ambiente e Desenvolvimento, 1992)

Por outro lado, a questão do desenvolvimento sustentável, em virtude da ameaça que representa ao futuro/presente da humanidade e pelas desigualdades que evidencia, ganhou inserção na agenda dos distintos setores e atores sociais, assim como na dos organismos internacionais. Em meio à constatação da gravidade dos problemas e das tendências atuais, alguns consensos vão-se estabelecendo:

"Prevenir os problemas de saúde e a deterioração do meio ambiente geralmente é mais humano e eficaz em função do custo de tratar e corrigir os danos já ocorridos. Para colocar em prática este conceito é necessário incluí-lo nos programas de todos os setores e organizações cujas atividades poderiam empurrar ou obstruir esta prevenção." (Conferência Panamericana de Saúde e Ambiente no Desenvolvimento Humano Sustentável, 1995)

Claro está também - como reconhece, por exemplo, o Banco Mundial - que é necessário comprometer os diferentes segmentos da sociedade de forma ativa e participativa para que esta perspectiva ganhe força política, de modo a difundir-se e ser incorporada nas iniciativas dos agentes econômicos e nas políticas públicas.

"Para que los procesos nacionales puedan llevarse a cabo dentro de un concepto de desarrollo humano sostenible, es preciso construir, consolidar, reforzar y/o perfeccionar las capacidades nacionales. (...) La necesaria visión integradora y holística que se espera de los dirigentes y recursos calificados de un país, necesita de nuevos perfiles en las profesiones, en los líderes de la sociedad civil, en los responsables políticos de los ámbitos, áreas y sectores sociales, y en aquellos que tienen funciones de gobierno." (OPAS, OEA, PNUD, PNUMA, BID e BANCO MUNDIAL, 1995:14)

Trata-se, assim, de um quadro desafiante. É possível antever a repetição de situações já verificadas em nosso país, se os atores sociais que poderão vir a sofrer os impactos negativos deste processo ou por eles poderão ser sensibilizados não interferirem em seu curso, como bem demonstra o trabalho de Franco (1997) sobre o Pólo de Camaçari: a migração de famílias na procura de emprego e a formação desordenada de centros urbanos em torno das empresas, onde vão se acumular problemas de moradia, saneamento, falta de acesso à educação e à saúde; violência; ruptura de raízes culturais e de coesão dos grupos sociais. Sobrepondo-se a isto, situa-se a difusão dos danos à saúde gerados por agentes nocivos - físicos, químicos, biológicos, ergonômicos e de acidentes - presentes nos ambientes de trabalho e que contaminam também o espaço de vida social, o ar, os rios, as praias e o solo.

\section{Capacitando profissionais}

Avaliando como cumprir sua função social diante deste quadro, a Universidade do Ceará identificou a necessidade de capacitar profissionais inseridos em posições estratégicas no tocante às questões que provocam impacto sobre a saúde e o meio ambiente, para qualificarem sua atuação com a orientação de contribuir na construção da sustentabilidade. Para isto, criou o Curso de Especialização em Saúde, Trabalho e Meio Ambiente para o Desenvolvimento Sustentável (Rigotto et al.,1997).

O Curso foi concebido para profissionais de diferentes formações básicas, que identificam seu campo de atuação profissional como pertinente ao do desenvolvimento sustentável. As vagas foram divididas entre agentes do serviço público, do setor privado e de Organizações Não-Governamentais - ONGs.

Visando empenhar as instituições com o aproveitamento do recurso humano capacitado, a indicação dos candidatos foi solicitada ao dirigente máximo das entidades, bem como o compromisso da liberação do profissional para as atividades do Curso. O processo de seleção dos alunos foi conduzido por banca de docentes de composição multidisciplinar, que tomou como base o caráter estratégico da inserção institucional do candidato, sua visão a respeito dos problemas socioambientais e sua abertura ao estudo interdisciplinar, explicitadas em questionário.

Assim, o corpo discente selecionado para a primeira turma - Curso que teve início em agosto de 1997 e que deverá ser concluído em novembro de 1998 - compõe-se de 32 profissionais: advogados, dentistas, cientistas sociais, enfermeiros, pedagogos, engenheiros, geógrafos, psicólogos, administradores de empresas, 
médicos, assistentes sociais, contadores e biólogos. Os servidores públicos são ligados a órgãos da administração municipal, estadual ou federal, responsáveis pelas questões de meio ambiente, saúde, assistência social, trabalho, educação e saneamento. Os do setor privado atuam diretamente na entidade de classe dos empresários industriais. Os demais estão inseridos em ONGs ambientalistas, em área de educação, em associações de profissionais e em sindicatos de trabalhadores.

O calendário do Curso - iniciado em agosto de 1997 e com término previsto para setembro de 1998 - foi organizado na primeira e terceira semanas de cada mês, de 16 às 20h, para permitir a freqüência dos alunos ao trabalho durante o seu desenvolvimento - fonte permanente de discussão e de avaliação crítica.

Ademais de estar sendo financiado com recursos do Fundo de Amparo ao Trabalhador, geridos de forma tripartite e administrados pela representação do Sistema Nacional de Emprego - SINE, no Ceará, o Curso conta com recursos oriundos da Fundação Jorge Duprat Figueiredo de Segurança e Medicina do Trabalho/FUNDACENTRO - instituição de pesquisa vinculada ao Ministério do Trabalho.

Com o objetivo de ampliar as discussões para público mais amplo de modo a trazer para a academia as preocupações dos diversos segmentos da sociedade, vários momentos do Curso são organizados na forma de Curso de Extensão, em que se abrem vagas para outros interessados.

O Programa do Curso está organizado em quatro módulos, totalizando 450 horas:

- Módulo I: Ampliando a compreensão do mundo em que vivemos. Pretende fornecer uma visão global do contexto internacional, nacional e regional em que se insere a problemática do Desenvolvimento Sustentável, situando as diversas abordagens deste conceito.

- Módulo II: Identificando problemas ambientais, de saúde e da produção no âmbito local. Tem como objetivo oferecer, aos alunos, metodologias e instrumentos para a identificação e avaliação de problemas relacionados à saúde, ao trabalho e meio ambiente em nível local, bem como traçar um perfil do quadro atual do estado do Ceará neste campo.

- Módulo III: Apropriando métodos e instrumentos para a melhoria da qualidade de vida. Pretende habilitar o aluno à intervenção preventiva sobre os problemas identificados, incluindo a formulação de políticas e o manejo de riscos/impactos, na perspectiva do Desenvolvimento Sustentável.

- Módulo IV: A Qualidade de Vida e a Política. Objetiva propiciar a compreensão das relações políticas que estão em jogo no processo de construção do Desenvolvimento Sustentável, capacitando o aluno a relacionar-se com os diversos atores sociais envolvidos na questão.

No Quadro 1 pode ser verificada a estruturação geral do Programa do Curso, as disciplinas que compõem cada módulo e sua carga horária.

\section{Desafio metodológico}

A complexidade da abordagem das relações entre saúde, trabalho e meio ambiente, compreendidas na perspectiva da construção de uma sociedade sustentável, exige metodologia interdisciplinar, como enfatiza Santos:

"O grande desenvolvimento das ciências particulares, durante este século, contribuiu para grandes avanços científicos e tecnológicos, mas, também, levou a uma extrema especialização do saber, cuja conseqüência é, freqüentemente, o próprio comprometimento do entendimento do mundo. (...) A denominada crise ambiental a que hoje assistimos padece dessa situação e deve suscitar uma revisão das teorias e práticas das diversas disciplinas na medida em que demanda uma análise compreensiva, totalizante, uma análise na qual as pessoas, vindas de horizontes diversos e que trabalhem com a realidade presente, tenham o seu passo acertado com o mundo, através de um legítimo trabalho interdisciplinar." (Santos, 1994:2)

Para Almeida Filho (1997), adotar metodologia interdisciplinar significa organizar o conhecimento científico a partir de uma práxis na qual os campos disciplinares não somente interagem entre si, mas também são construídos pelos sujeitos na prática científica cotidiana. $\mathrm{O}$ autor enfatiza que os sujeitos da ciência seriam essencialmente 'agentes sociais'. Sugere ainda que a interdisciplinaridade alcança a transdisciplinaridade quando a comunicação passa a ser estabelecida não entre os campos disciplinares nem através da tradução dos diferentes discursos das diversas disciplinas, mas, sim, mediante a comunicação entre os ‘agentes' em cada campo e por 
Quadro 1

Programa do curso de especialização em saúde, trabalho e meio ambiente para o desenvolvimento sustentável.

Módulo 1: Ampliando a compreensão do mundo em que vivemos

Disciplinas obrigatórias

- Desenvolvimento Sustentável no contexto da Globalização e da Reestruturação Produtiva - 45h

- Estado e Políticas Públicas para o Desenvolvimento Sustentável - 30h

Disciplina optativa

- Introdução à Internet - 15h

\section{Módulo 2: Identificando problemas ambientais, de saúde e da produção no âmbito local}

Disciplinas obrigatórias

- Economia Regional e seus impactos sobre a Saúde, o Trabalho e o Meio Ambiente no Ceará - 30h

- Análise de Riscos/Impactos nos Locais de Trabalho e no Meio Ambiente - 30h

- Conhecimento e Sociedade $-30 \mathrm{~h}$

- Sociologia do Trabalho - 15h

Disciplinas optativas

- Doenças Profissionais e do Trabalho - 30h

- Saúde Mental e Trabalho - 15h

- Avaliação de Aspectos Físicos do Meio Ambiente - 15h

Módulo 3: Apropriando métodos e instrumentos para a melhoria da qualidade de vida

Disciplinas obrigatórias

- Noções de Legislação Trabalhista e Sanitária - 30h

- Planejamento Ambiental - 30h

- Manejo de Riscos no Trabalho e no Ambiente - 30h

- Planejamento e Avaliação de Políticas Públicas - 15h

- Legislação Ambiental - 15h

- Negociação de Conflitos - 15h

Disciplina optativa

- Organização das Ações de Atenção à Saúde dos Trabalhadores - 15h

Módulo 4: A qualidade de vida e a política

Disciplinas obrigatórias

- Movimentos Sociais e Desenvolvimento Sustentável - 30h

- Comunicação - 15h

Módulo 5: Avaliação - apresentação das monografias

meio do trânsito dos sujeitos dos discursos. O estudo a respeito do mundo do trabalho, saúde e meio ambiente - assim como das suas relações com o processo de globalização da economia e as possibilidades da construção de uma sociedade sustentável - é considerado objeto complexo, multifacetado; daí a necessidade de ser observado e vivenciado a partir do 'cruzamento' de distintos discursos disciplinares e agentes sociais diversos.

Como construir esta abordagem na prática de ensino? Especial atenção está sendo dedicada a esta questão.
Em primeiro lugar, desde a concepção do Curso e elaboração do Programa, buscou-se o trabalho conjunto entre quatro áreas de conhecimento, organizadas nos Departamentos de Saúde Comunitária, Geografia, Ciências Sociais e Filosofia e de Enfermagem. Outros docentes e profissionais das áreas de Economia, Direito, Psicologia, Comunicação e Informática - alguns deles inseridos em ONGs - também foram convidados a contribuir no desenho e implantação do Programa.

Além da construção compartilhada do objeto de ensino-aprendizagem, tem-se estimu- 
lado também a interlocução entre os docentes ao longo do Curso. Os objetivos, conteúdos, metodologia e bibliografia de cada disciplina são elaborados pelo professor responsável à luz das discussões conjuntas e, então, apresentados ao corpo de professores. Neste coletivo são analisadas as interfaces, a sintonia com os marcos teóricos e metodológicos estabelecidos pelo grupo e as possibilidades de abordagem conjunta.

A estrutura modular concebida para o Curso, por sua vez, possibilita o diálogo entre as diversas disciplinas em torno do eixo unitário. Um exemplo concreto: ao ser discutido o programa da disciplina Saúde Mental e Trabalho - elaborado por uma psicóloga, economistas e sociólogos -, diante da possibilidade dos sérios impactos da Reestruturação Produtiva sobre os níveis de emprego, seus organizadores alertam para a premência de nele serem abordadas também as relações entre desemprego e saúde mental.

Desta forma, tem sido freqüente que professores assistam aulas de outros durante o Curso, motivados a ampliar sua compreensão. Outras vezes, durante suas aulas, conhecendo o Programa das outras disciplinas, são capazes de indicar pontes para os alunos ou de estimulá-los a identificá-las e de se referirem à bibliografia adotada em outras matérias. Também acontece de algumas aulas ou mesmo algumas disciplinas exigirem a presença simultânea de mais de um professor de áreas de conhecimento distintas. Foi o caso, por exemplo, da 'Análise de Riscos/Impactos nos Locais de Trabalho e no Meio Ambiente', ministrada por um geógrafo e um higienista do trabalho, no esforço de construir uma metodologia de avaliação de riscos/impactos que não se interrompesse 'no muro da fábrica', mas que pudesse contemplar, de modo adequado e na prática, o estudo das relações entre produção e meio.

Tem-se buscado ainda a organização de atividades transdisciplinares com base em estudos de campo orientados por professores de diferentes disciplinas. Neles, a realidade, enquanto sistema complexo, não só permite a intervenção de um olhar multifacetado sobre o objeto, como a exige.

Há que considerar igualmente o papel dos alunos sob o aspecto de sujeitos ativos no processo ensino-aprendizagem, na construção da abordagem interdisciplinar. Sua abertura para o estudo de disciplinas não necessariamente ligadas diretamente a sua área de formação básica foi critério para avaliação dos candidatos ao Curso e de seleção dos alunos. Este desafio metodológico tem sido permanentemente discutido com a turma e, pelas avaliações que eles fazem de cada disciplina, parece já ter-se constituído como valor para o grupo. $\mathrm{O}$ próprio perfil multiprofissional e plurisetorial dos alunos tem sido fator propiciador da abordagem do objeto em suas várias dimensões e em sua complexidade.

Também a avaliação do aproveitamento dos alunos tem sido proposta de forma a estimular neles a tessitura ativa da integração entre as áreas de conhecimento e a reflexão sistemática acerca de sua prática profissional-institucional que, estando inserida diretamente na realidade, abre espaço à interdisciplinaridade. Tem-se investido na construção de um discurso mediante o qual os professores criem a possibilidade da apreensão, por parte dos alunos, da necessidade de transformação da práxis institucional na qual se inserem.

Foram criados ainda dois instrumentos facilitadores da participação e da integração. O primeiro, é um Colegiado de Coordenação do Curso, composto por um professor de cada Departamento envolvido na sua implantação e por dois representantes dos alunos, encarregado do processo permanente de acompanhamento, avaliação e direção do Curso. O outro, é um boletim que circula entre docentes, alunos, instâncias universitárias e entidades parceiras, socializando informações sobre o desenvolvimento do Curso, as avaliações das disciplinas, as dificuldades, as demandas específicas de contribuição etc.

Algumas dificuldades têm-se apresentado neste processo. A primeira delas está relacionada à delimitação dos conteúdos em um campo temático tão abrangente: tudo parece interessar à sociedade sustentável! É possível/desejável conciliar a compreensão mais ampla das grandes questões que afligem a humanidade com a capacitação técnica específica em tantas áreas? Sabemos que não há um perfil esperado de aluno como produto do Curso, já que são múltiplos os perfis necessários à transformação. Como contemplar esta multiplicidade em um Programa, em sala de aula? Às vezes, alguns alunos falam da sensação de superficialidade, do interesse em aprofundar mais certos temas técnicos ou específicos, enquanto outros reclamam que 'isto é coisa para especialista'. Nestas situações - muito férteis para a discussão da crise epistemológica atual 
e seus desafios - tem sido reforçada a importância da constituição de capacidade para o trabalho em equipes multiprofissionais/interdisciplinares, nas quais, com a prática dialógica entre os sujeitos, pode ser construída e compartilhada uma visão geral do objeto e na qual cada especialista tem espaço para sua contribuição específica. Vai ficando clara igualmente a necessidade de capacitação de cada um para o investimento no seu campo próprio de interesse, conhecendo onde buscar informação e sabendo avaliá-la criticamente.

Muito esforço tem sido exigido de todos nós, professores, para acompanharmos esta trajetória epistemológica rumo à interdisciplinaridade, em razão mesmo de nossa formação universitária não ter sido efetuada dentro deste marco e por esta abordagem ainda ser instituinte na vida acadêmica. Há dificuldades, no plano objetivo, referentes à construção de linguagem comum entre as áreas, assim como à disponibilidade de estudos e bibliografia que não reforcem a segmentação do saber, entre outras. Mas parece haver também questões relacionadas ao plano subjetivo: é como se o saber que cada um já domina pudesse ser 'ameaçado' em sua relevância pelo convite à nova abordagem; ou como se o sujeito estivesse sendo colocado diante de enorme cobrança de reestudo; acentua-se, por sua vez, o sentimento de insegurança no caminhar para metodologia que ainda não está pronta, que se faz no fazer de cada um. Tudo isto, é claro, convivendo com o desejo de avançar, de conhecer, experimentar o novo.

\section{Os produtos do trabalho acadêmico}

A preocupação permanente com o papel do Curso no processo de construção de uma sociedade sustentável tem trazido um direcionamento para a produção acadêmica. Em um primeiro nível, os trabalhos de avaliação dos alunos em algumas disciplinas têm sido voltados para uma reflexão crítica sobre a própria práxis: como a globalização e a reestruturação produtiva rebatem sobre meu objeto de trabalho? Como a reforma de estado está acontecendo no Ceará? Em que medida as políticas públicas que coordeno/implanto apontam para a sustentabilidade? Que papel a ONG em que me insiro tem desempenhado? Alguns alunos já têm declarado os efeitos destas reflexões sobre seu trabalho.
Outro nível de produção acadêmica com retorno imediato à sociedade: a disciplina 'Avaliação de Aspectos Físicos do Meio Ambiente' culminou com um estudo de campo no geossistema da Serra de Baturité, em que ficou demonstrado a importância de conhecer o ambiente - relevo, solo, clima, hidrografia, fauna e flora - para elaborar o Plano Diretor ou de Saúde ou Agrícola de cada município que o compõe. $\mathrm{O}$ estudo de campo foi filmado por alunos e está sendo editado para ser oferecido, como subsídio, às autoridades municipais e às organizações da sociedade civil na região. Nesta mesma linha, os relatórios de visitas a empresas para avaliação de riscos ocupacionais também são preparados para retornar a elas.

Os Trabalhos de Conclusão de Curso estão em fase de anteprojeto neste momento (abril/ 98). Os alunos foram estimulados a eleger temas relevantes para a construção de uma sociedade sustentável e a recortar objetos que venham a propiciar a transformação das práticas institucionais em que estão inseridos. Os anteprojetos foram apresentados e discutidos coletivamente. Na definição dos orientadores, reaparece a questão da interdisciplinaridade: vários alunos indicaram dois ou três professores de áreas distintas, expressando a necessidade de criar novas formas de orientação dos trabalhos acadêmicos que contemplem estas exigências. O Curso deverá culminar com a apresentação destes trabalhos, organizada não só para o meio universitário, mas envolvendo também as entidades de origem dos alunos e outras organizações da sociedade civil.

\section{Considerações finais}

Com a implantação do Curso de Especialização em Saúde, Trabalho e Meio Ambiente para o Desenvolvimento Sustentável, tem-se buscado responder a exigências colocadas para a sociedade em função da nova ordem mundial que, por sua vez, demanda da academia a reunião de áreas de conhecimento tradicionalmente constituídas de forma mais ou menos isolada - como a saúde, o trabalho e o meio ambiente. $\mathrm{O}$ estudo destas relações complexas tem colocado para professores e alunos o desafio de participar de um movimento mais amplo de construção de uma metodologia de trabalho interdisciplinar também para o processo ensino-aprendizagem. 
O caminho metodológico que vem sendo percorrido por professores, alunos e coordenação do 'Curso de Especialização em Saúde, Trabalho e Meio Ambiente para o Desenvolvimento Sustentável' tem assinalado o desejo de avançar e experimentar o novo a partir dessa nova compreensão da interdisciplinaridade e, provavelmente, o alcance da transdisciplinaridade, desde que forme agentes históricos comprometidos com transformações das práticas institucionais nas quais estão inseridos.
Embora envolva grande esforço, é evidente para o grupo que, no momento, este é condição necessária para alcançar o objetivo de capacitar pessoas para participarem no atual momento histórico rumo a uma compreensão holística da sustentabilidade para todos, inclusive para os que virão.

Partilhar esta experiência é também uma busca de canais de interlocução para o enriquecimento recíproco.

\section{Referências}

Almeida Filho N 1997. Transdisciplinaridade e saúde coletiva. Revista Ciência e Saúde Coletiva II: 1/2:5-20.

Bacelar TA 1997. Herança de diferenciação e futuro de fragmentação. Revista de Estudos Avançados da USP 29: 7-36.

IPLANCE - Instituto de Planejamento do Ceará 1997. Principais resultados da Pesquisa Nacional por Amostragem de Domicílios - PNAD/IBGE - 1995 e 1996. IPLANCE, Fortaleza.

Conferência das Nações Unidas sobre Meio Ambiente e Desenvolvimento 1992. Declaração do Rio sobre Meio Ambiente e Desenvolvimento. Rio de Janeiro.

Conferência Pan-Americana de Saúde e Ambiente no Desenvolvimento Humano Sustentável 1995. Carta Pan-Americana para a Saúde e o Ambiente, Washington, D.C.

Franco T 1997. Trabalho, Riscos Industriais e Meio Ambiente: Rumo ao Desenvolvimento Sustentável? EDUFBA/CRH/FFCH/UFBA, Salvador.
Organización Panamericana de la Salud, Organización de los Estados Americanos, Programa de las Naciones Unidas para el Desarrollo, Programa de las Naciones Unidas para el Medio Ambiente, Banco Interamericano de Desarrollo, Banco Mundial 1995. Américas en Armonía - La Salud y el Ambiente en el Desarrollo Humano Sostenible. Washington, D.C.

Rattner H 1997. Globalização: em direção a um mundo só? In B Becker \& M Miranda (orgs.) - A Geografia Política do Desenvolvimento Sustentável. Ed. UFRJ, Rio de Janeiro.

Rigotto R, Almeida V, Araújo N \& Silva E 1997. Projeto de Criação do Curso de Especialização em Saúde, Trabalho e Meio Ambiente para o Desenvolvimento Sustentável. Universidade Federal do Ceará, Fortaleza, mimeo.

Santos M 1994. A Questão do Meio-ambiente: Desafios para a Construção de uma Perspectiva Transdisciplinar, mimeo. 